\title{
A Comparison of Least-to-Most Prompting and Video Modeling for Teaching Pretend Play Skills to Children with Autism Spectrum Disorder
}

\author{
Burcu Ulke-Kurkcuoglu ${ }^{a}$ \\ Anadolu University
}

\begin{abstract}
The aim of this study is to compare effectiveness and efficiency of least-to-most prompting and video modeling for teaching pretend play skills to children with autism spectrum disorder. The adapted alternating treatment model, a single-subject design, was used in the study. Three students, one girl and two boys, between the ages of 5-6 participated in the study. The effectiveness results of the study showed that there is no marked difference between least-to-most prompting and video modeling for teaching pretend play skills to children with autism spectrum disorder in terms of acquisition, maintenance, and generalization. However, when these two teaching processes are compared in terms of efficiency parameters, it was observed that teaching with least-to-most prompting is more efficient in comparison to video modeling for two subjects. The social validity findings of the study showed that the mothers of the subjects and the graduate students who studied and had already taken certain courses for their master's degree in the Applied Behavior Analysis Program expressed positive opinions about the study. Findings obtained from the study were discussed and suggestions were given for further studies.
\end{abstract}

Keywords: Autism spectrum disorders $\bullet$ Video modeling $\bullet$ Least-to-most prompting $\bullet$ Pretend play

a Correspondence

Assist. Prof. Burcu Ulke-Kurkcuoglu (PhD), Research Institute for the Handicapped, Anadolu University, Yunus Emre Campus, Eskisehir 26470 Turkey

Research areas: Applied behavior analysis, children with autism spectrum disorder and their education Email: bulkekurkcuogludanadolu.edu.tr 
One of the fundamental problems of individuals with Autism Spectrum Disorder (ASD) is the failure in social interaction and communication skills. These failures constitute a significant part of the criterion included in guidelines published by the American Psychiatric Association (APA) for ASD diagnosis from past to present $(2001,2013)$. It is seen that failures in symbolic and scenario play take place in the DSM-IV-TR (Diagnostic and Statistical Manual of Mental Disorders) under the developmental process category of communication disorders titled as improper playing skills (KircaaliIftar, 2012). According to the DSM-5, the most recent edition, failures in developing, maintaining, and understanding relationships are emphasized within the category of social interaction and communication disorders. Failures such as difficulty in sharing pretend play or having friends come to the forefront in this sub-category (APA, 2013). Therefore, it is seen that failures in pretend play skills have a vital role in the diagnosis of individuals with ASD.

Play is an enjoyable, spontaneous activity in which children actively discover the world around them and bridge the gap between dreams and reality. They gain new experiences with people, objects and events using current knowledge, providing intrinsic motivation (Wolfberg, 1999). It is also an effective educational process supporting the development of a child's cognitive, lingual, social-emotional, and physical aspects (Lifter, Foster-Sanda, Arzamarski, Briesch, \& McClure, 2011; Phillips \& Beavan, 2012). Pretend play has an important role among early childhood play because it is emphasized in literature that pretend play in particular among the types of play is an early indicator of cognitive, social, and language skills (Barton \& Pavilanis, 2012; Barton \& Wolery, 2008; Lam \& Yeung, 2012). Barton and Wolery (2008) stated that performing a series of interrelated realistic activities in pretend play can provide a basis for higher levels of thinking and reasoning. While pretend play is experienced at a basic level in early periods, it can turn into more complicated play to which symbolic components are added in parallel with development. Four different types of pretend play are listed : (a) functional play with pretense (a child can take an empty cup and pretend to drink water), (b) object substitution (a child can use a block as if it is a car), (c) imagining absent objects (a child can hold their hand up to the doll's mouth pretending to feed it.), and (d) assigning absent attributes (a child can take the doll on their lap and say, "The baby is ill,") as per Barton \& Pavilanis (2012) and Ulke-Kurkcuoglu (2012). In addition to these types, pretend play also has two different features: sequences and vocalization. The sequences feature is when at least two pretend play behaviors are displayed which are related to the play theme and sequence. For example, stirring a spoon in a bowl and putting the spoon up to the doll's mouth. There are two types of vocalizations including confirmatory vocalization and related vocalization. Expressions such as "I am cooking," or "I am feeding my baby," which determine or confirm pretend play behaviors, are used in confirmatory vocalization. In related vocalization, expressions defining the action or toys during play (e.g. "The oven is hot!") are used (Barton, 2010).

Children with ASD show a lower variety of pretend play skills at a basic level with lower frequency, compared to their peers who show typical development or other developmental disabilities (Barton \& Wolery, 2008; Rutherford, Young, Hepburn, \& Rogers, 2007). Failures of children with ASD in social interaction and communication skills limit their pretend play skills and form a basis for these pretend plays to show themselves as self-stimulatory behaviors (Barton \& Pavilanis, 2012; Hobson, Hobson, Malik, Bargiota, \& Calo, 2013; Lovaas, 2003). Limitations with their play skills complicate natural communication with their peers and being accepted to play with peers. Therefore, children with ASD should learn pretend play skills to understand life events, the relationships among people, and the emotions and thoughts about events; to interact with peers; to develop mental functions such as creative thinking in play, problem solving, and reasoning; and to gain support from communication and language skills (Barton \& Pavilanis, 2012; Phillips \& Beavan, 2012). Researchers suggest that pretend play skills should be ranked among the primary instructional objectives and these skills should be taught systematically (Barton \& Pavilanis, 2012; Barton \& Wolery, 2008). In the literature, there are a wide range of studies in which pretend play skills are taught to individuals with ASD using different teaching methods (Barton, 2010; Hobson, Lee, \& Hobson, 2009; Kasari, Freeman, \& Parapella, 2006; McDonald, Sacramone, Mansfield, Wiltz, \& Aheran, 2009). Barton (2010) reports in his review article that pretend play is emphasized in literature because it is a significant matter for children with ASD, but the types and features of pretend play in these studies show inconsistency. Therefore, this study suggests that further studies should be planned within the scope of all predefined pretend play types and their features. 
Nowadays the importance of treatments that provide scientific basis, such as the errorless teaching model and video modeling for teaching several skills to individuals with ASD, has been emphasized (Wong et al., 2014). Least-to-most prompting, which is one of the errorless teaching models, is also one of the interventions that provide scientific basis. The least-to-most prompting procedure starts with a presentation of the least restrictive prompt for an individual, and the type and intensity of the prompt are changed as needed, gradually skipping to the most restrictive prompt. Transition between levels of prompt occurs when an individual does not respond during the prescribed response time. In this teaching model, for example, a prompting hierarchy which consists of at least three levels, no prompt, gestural prompt, and physical prompt for example, is created (Tekin-Iftar \& KircaaliIftar, 2013). In an intervention session, one target stimulus is provided at first and the individual is expected to give a correct response in the given response time. If the individual provides the correct response, he/she is reinforced. If the individual gives an incorrect response or does not respond, the teacher presents the first prompt level in the prompt hierarchy and waits for the response of individual. If the individual then gives the correct response, he/she is reinforced. If the individual gives the incorrect response again or does not respond, the teacher delivers the second prompt level and waits for a response. Presentation of the prompts is carried on in this way until the individual gives the correct response or the teacher delivers all prompts in the hierarchy (Ault \& Griffen, 2013).

There are considerable studies related to leastto-most prompting which extend far back in the literature, showing that it is effective in teaching several skills to individuals of different ages with developmental disabilities (Ault \& Griffen, 2013). When recent studies conducted on individuals with ASD are examined, it is seen that least-tomost prompting was effective on teaching pretend play (Barton \& Wolery, 2010); for using an iPod to ease transition between activities (Cihak, Fahrenkrog, Ayres, \& Smith, 2010); and for playing tennis (Yanardag et al., 2011). Researchers suggest the use of least-to-most prompting, especially in teaching pretend play skills, is effective due to the following reasons: (a) it supports playing alone because it gives a chance to respond independently, (b) it can be embedded effectively in adult-child interactions, and (c) by use of prompts based on play interaction, it motivates a child toward new play behaviors (Barton \& Wolery, 2008, 2010). It was discovered that there are a limited number of studies where pretend play skills have been taught to individuals with ASD through least-to-most prompting (Barton \& Wolery, 2010; Kasari et al., 2006; Lifter, Ellis, Canon, \& Anderson, 2005; Lifter, Sulzer-Azaroff, Anderson, \& Cowdery, 1993). When the studies in question were examined, it was seen with the exception of two studies, the other studies were limited in procedural aspects. Barton and Wolery (2010) examined the functional relationship between teacher use of least-to-most prompting, imitation, and reinforcement together while teaching pretend play to four individuals with this disorder. As a result, an increase in pretendplay behaviors was observed in the children. Kasari et al. (2006) conducted an experimental research in which 58 children with ASD were divided into two experimental groups and one control group using random assignment. Joint attention was taught to one experimental group while symbolic play including least-to-most prompting was taught to the other experimental group. In this study it was observed that the children in the symbolic-play group performed symbolic play in different ways and at higher levels.

Video modeling is also included in evidence-based practices and used frequently in the education of individuals with ASD. During video modeling, which is based on Bandura's observational learning theory, a video is recorded while a model (an adult, peer, or oneself) displays a target skill. The individual watches this video. Afterwards, he or she is expected to demonstrate the same skill by imitating the performance of the model (Mason, Ganz, Parker, Burke, \& Camargo, 2012; ShuklaMehta, Miller, \& Callahan, 2010). In an intervention session where video modeling is performed, an individual's attention is drawn to focus on the screen, and then the individual is made to watch the video. Skill instruction related to a target skill is delivered and the individual is expected to display this target behavior according to the model (Shukla-Mehta et al., 2010). Video modeling can be used by itself in this way as well as together with different teaching methods such as reinforcement and social stories (Mason et al., 2013).

It can be seen in the literature that video modeling is effective mostly in teaching the skills of social communication, play, adaptive, academic and selfcare to individuals with ASD (Mason et al., 2013; Shukla-Mehta et al., 2010). Also, it is observed that skills such as hand washing (Rosenberg, Schwartz, \& Davis, 2010), gestures, and facial expressions 
(Charlop, Dennis, Carpenter, \& Greenberg, 2010), playing (Palechka \& MacDonald, 2010), and vocational skills (Allen, Wallace, Renes, Bowen, \& Burke, 2010) were taught using video modeling. These results are effective when examining recent studies conducted on individuals with ASD. A large number of studies in which pretend play skills are taught to individuals with ASD via video modeling are included in the literature (Boudreau \& D'Entremont, 2010; MacDonald et al., 2009; Scheflen, Freeman, \& Paparelle, 2012). The effects of video modeling on teaching intended pretend play behaviors and verbal expressions related to play for children with ASD were examined in these studies. The results of these studies showed that video modeling was effective and children with ASD learned both play behaviors and verbal expressions. Shukla-Mehta et al. (2010) suggest in their review article that studies, which the effects of video modeling are compared, should be conducted through performing it with participants from different cultures via prompting methods provided by teacher, although there are a large number of studies about video modeling.

There are several studies conducted which compare the effects of either least-to-most prompting or video modeling when used along with different treatments during the teaching process of various skills including play skills especially to individuals with ASD (Charlop-Christy, Le, \& Freeman, 2000; Libby, Weiss, Bancroft, \& Ahearn, 2008; Sancho, Sidener, Reeve, \& Sidener, 2010). However, only one study was found in which the effect and efficiency of presenting least-to-most prompting alone and together with video modeling were compared (Murzynski \& Bourret, 2007). Murzynski and Bourret (2007) compared the effects and efficiency of these two interventions for teaching chained skills such as how to prepare fruit juice, make a sandwich and fold clothes to two children with ASD. The resulting effect of their study showed that there were no differences between these two interventions while the efficiency result of it revealed that presenting least-to-most prompting together with video modeling is more efficient in comparison to presenting it alone. Furthermore, two studies were found where the comparative studies were discussed in terms of teaching pretend play skills, also including role-play skills, to individuals with ASD (Akmanoglu, Yanardag, \& Batu, 2014; Lydon, Healy, \& Leader, 2011). The effect and efficiency of video modeling and pivotal response training on teaching pretend play skills to children with ASD were compared in the study conducted by Lydon et al. (2011). Akmanoglu et al. (2014) compared the effect and efficiency of presenting video modeling alone and together with graduated guidance on teaching role-play skills to children with ASD. It was suggested in these three studies that further studies should focus on comparing video modeling with teaching methods based on different response prompts. Moreover, there has been no study where the effect and efficiency of video modeling and least-to-most prompting, which has been suggested particularly in recent years, on teaching pretend play skills to individuals with ASD were compared. Considering all of these reasons, the purpose of the present study is to determine whether the effect and efficiency of presenting least-to-most prompting and video modeling are different when teaching pretend play skills, including all of the pretendplay types and features, to children with ASD. The following research questions were addressed to find answers in line with this purpose. Do the effects of least-to-most prompting and video modeling differ on teaching pretend play skills to children with ASD in acquisition, maintenance, and generalization? Is there any difference between these two interventions in terms of the number of sessions, trials and total time spent for teaching and the number/percentage of incorrect responses? What are the opinions of the graduate students, having already taken the courses of Applied Behavior Analysis II and III in their master's degree program for Applied Behavior Analysis, and the opinions of the subjects' mothers about the aims of the study and the interventions used for achieving these purposes?

\section{Method}

\section{Participants}

Subjects: The participants of the study were three students, one girl and two boys between the ages of 5-6. The prerequisite skills required of the subjects for participation in the study were identified as being able to: (a) engage in an activity for at least 5 minutes, (b) imitate verbal expressions, (c) have gross and fine imitation skills, (d) perform simple instructions, (e) make a minimum of two or more word sentences, $(f)$ have functional play skills, $(g)$ watch a video on the laptop screen for at least 2 minutes, and (h) have gross and fine motor skills adequate for performing the steps during the skill analysis of the pretend play skills targeted for teaching. The responses of the subjects were observed in activities both planned to test their prerequisite skills and performed by the class teacher within the context of determining whether they had the prerequisite skills or not to continue 
the group teaching. As a result of this observation, it was determined that they had the necessary prerequisite skills to participate in the study.

Parental permission was received for participation of the subjects in the study. Aliases were given to the subjects and the characteristics of the subjects are defined below:

Sude is a six-year-old female student. According to the report which was received from a public hospital and provided by her parents, she had been diagnosed with atypical autism. Sude was tested using the Leiter International Performance Scale, a test standardized by the Guidance and Research Center (GRC). Her IQ was determined to be 80. In order to detect the occurrence possibility of autistic disorder for Sude, an evaluation was carried out using the Gilliam Autism Rating Scale2-Turkish Version. As a result of this evaluation, it was discovered that Sude measures at $13 \%$ in stereotypical behaviors, $69 \%$ in communication skills, and $13 \%$ in social interaction skills. For this reason, it was concluded that the occurrence possibility of autistic disorder for Sude was high because her standard score was 88 with regard to the autistic disorder index. Sude has received group education from the Unit for Children with Developmental Disabilities five half-days a week for a year and also has enrolled in a private preschool. Sude has matching, imitation, gross, and fine motor skills. She also shows functional play skills such as being able to do jigsaw puzzles and play with shaped blocks. She can follow verbal expressions made up of two or more words and she can state two-word expressions. She can pay attention to the activities for at least 5 minutes and complete an activity she begins. Sude can watch a video on the laptop screen for at least two minutes.

Ali is a five-year-old male student. According to the report which was received from a public hospital and provided by his parents, he was diagnosed with childhood autism. He was tested using the Leiter International Performance Scale and was determined to be untestable. In order to detect the occurrence possibility of autistic disorder for Ali, an evaluation was carried out using the Gilliam Autism Rating Scale-2-Turkish Version. According to the result of this evaluation, he was measured at the rate of $86 \%$ in stereotypical behaviors, $79 \%$ in communication skills, and $69 \%$ in social interaction skills. Because his standard score was determined to be 114 with regard to the autistic disorder index, it was concluded that the occurrence possibility of autistic disorder for Ali was very high. Ali has received group education from the Unit for Children with Developmental Disabilities five halfdays a week for a year. He has matching, imitation, gross, and fine motor skills. He also shows functional play skills such as being able to do jigsaw puzzles and play with shaped blocks. He can follow verbal expressions which are made up of two or more words and he can state two-word expressions talking very quickly. He can pay attention to the activities for at least 5 minutes and can complete an activity he begins. He can watch the video on the laptop screen for at least two minutes.

Emre is a five-year-old male student. According to the report which was received from a public hospital and provided by his parents, he was diagnosed with autism. Emre was tested using the Leiter International Performance Scale and he was determined as untestable. In order to detect the occurrence possibility of autistic disorder for Emre, an evaluation was carried out using the Gilliam Autism Rating Scale-2-Turkish Version. As a result of this evaluation, it was discovered that Emre was measured at a rate of $58 \%$ in stereotypical behaviors, $86 \%$ in communication skills, and $58 \%$ in social interaction skills. For this reason, it was concluded that the occurrence possibility of autistic disorder for Emre was very high because his standard score was detected as 107 with regard to the autistic disorder index. Emre has received group education from the Unit for Children with Developmental Disabilities five half-days a week for a year and has also enrolled in a private preschool. Emre has matching, imitation, gross and fine motor skills. He also shows functional play skills such as being able to do jigsaw puzzles and play with shaped blocks. He can follow verbal expressions which are made up of two or more words and state two-word expressions in an understandable way. He can pay attention to the activities for at least 5 minutes and can complete an activity he begins. Emre can watch the video on the laptop screen for at least two minutes.

Peers: Peer modeling was used for the video modeling process. Video records were prepared together with two willing peer models, who accepted to take part in the study in order to be used for this process. One of the peer models was a girl and the other was a boy. Both of them were 8 years old and in the second grade. Skill analyses for each pretend play skill were prepared by the author as a trainer and for their evaluation these analyses were given to three experts who hold doctorates in special education. The experts deemed the skill 
analyses convenient and confirmed them. Before videos were recorded with the peer models, the research environment where the study would be conducted, the materials, and the reinforcements which would be given to the peers were prepared. Until all steps in the skill analyses were performed correctly at the rate of $100 \%$, each step was rehearsed with the peers. Afterwards, the video records of the peers were captured while they displayed pretend play targeted to be taught in conformity with the skill analysis steps by using the necessary materials for the play skills. These videos were recorded between 1 minute 2 seconds and 1 minute 17 seconds in duration, paying heed to the attention spans of the subjects. Video records were given to experts working in the area of special education for their evaluation and the experts were requested to fill the Video Validity Form prepared by the trainer while watching the video recordings. Thus, the video recordings were ensured in terms of validity. The experts filled the forms and pointed out that the peers performed every pretend play skill in compliance with the skill analysis steps while they were watching them.

\section{Settings and Materials}

All sessions with the subjects of the study except for generalization sessions took place in one of the personal study rooms located in the Unit for Children with Developmental Disabilities at Anadolu University. Two tables were placed in the room. One of the tables was used for watching videos and the other one was used for playing. Two chairs were placed in the room at both of the tables. Cabinets with shelves were also placed for the storage of educational materials. Plastic containers for play materials were placed on one of the shelves. Generalization sessions were conducted in a play room, and tables and chairs were not used.

During the study, the materials that were used are listed here: $(a)$ a video camera and tripod for recording the sessions in the study process; $(b)$ a laptop for the video records watched during intervention sessions and for the videos that were prepared by converting video records of the peer models into video clips; $(c)$ materials for each pretend play skill and plastic containers for placing them in; and $(d)$ reinforcers. Furthermore, data collection forms were used for the probe, intervention, maintenance, and generalization sessions to keep track of student performance with regard to each target behavior.

\section{Experimental Design}

An adapted alternating treatment design was used in order to compare the effects and efficiency of least-to-most prompting and video modeling for teaching pretend play skills to children with ASD. An adapted alternating treatment design is a research model used for comparing the effects of two or more independent variables on two or more nonreversible, dependent variables (Kurt, 2012; TekinIftar \& Kircaali-Iftar, 2013). Experimental control is accomplished using a faster change in level or trend of a dependent variable related to an independent variable than the change in level or trend of the dependent variable related to another independent variable in an adapted alternating treatment design (Tekin-Iftar \& Kircaali-Iftar, 2013). Four points were observed to provide the necessary conditions for the implementation process of the adapted alternating treatment design model in this study. First of all, pretend play pairs were determined with regard to difficulty of fine motor skills, types and features of pretend play, features as well as number of sounds, words and sentences in verbal expressions, and starting of verbal expressions in pretend play with different words. Pairs are functionally similar but independent of each other, as determined by difficulty level analysis. Second, fast alternations of least-to-most prompting and video modeling, which are independent variables, was ensured. Implementing both of these teaching treatments at different times in a day, with at least a one-hour break between them, was taken into account in terms of this alternation. Third, the number of treatment sessions was equal in both teaching processes. Fourth, a balanced distribution of all variables was ensured, such as the reinforcers and the schedule of reinforcements, except for the variables peculiar to teaching methods.

\section{Dependent and Independent Variables}

The independent variables of the study consisted of pretend play pairs and difficulty levels, the number of which were equal for each subject. Play was taken into account in terms of the similarities in function and independence from each other while they were selected. Which pretend play would be taught was determined through random assignment to least-to-most prompting and video modeling. A list consisting of potential pretend play skills in accordance with the developmental levels of preschoolers was arranged in order to determine which pretend play skill to use. Afterwards, the teacher and mothers of the subjects were asked 
to express their personal opinions about which play they wanted their children to be taught. The teacher carefully chose the pretend play skills which they wanted to be taken a particular part in the individualized education program for the subject or that they had already taken part in. The mothers also determined which play choices they thought would help at home or in preschool. The pretend play choices were determined in light of the common preferences of both teacher and mothers, and skill analyses for these play choices were carried out. The pretend play types which were suggested by Barton and Pavilanis (2012) and listed below were taken into account for embedding in all steps of the play skills: (a) functional play with pretense, as in a pizza-making play skill using a toy oven; (b) object substitution,such as using a block like salt; (c) imagining absent objects/events/situations such as acting as if there is a bowl with dough; and (d) assigning absent attributes, as in pretending the subject is a pizza maker. Furthermore, the sequence of pretend play and vocalization features listed below were also embedded in the target play skills: (a) sequence features, such as when a child takes a flour pack and pretends to pour flour into the bowl and $(b)$ confirmatory and related vocalizations, such as the use of expressions like "let's make pizza," with the aim of confirmatory vocalization or "the oven is hot," for the purpose of related vocalization. These were placed in the making-pizza play activity. The convenience of the prepared-skill analyses was evaluated by three experts, all holding doctor's degrees in special education, and the skill analyses took their final forms in the light of their evaluations. Afterwards, video clips were created for the video modeling process. The skill analyses of pretend-play pairs targeted to be taught to each subject are displayed in Table 1.

The independent variables of the study are least-tomost prompting and video modeling. A prompting hierarchy was used for the least-to-most prompting method in three different levels: independent from prompt, gestural prompt plus verbal prompt, and physical prompt plus verbal prompt. Until the subjects give the correct responses or all prompts of the hierarchy are performed, a transition from independent-of-prompt level to physical-promptplus-verbal-prompt level was followed. The subjects were made to watch video records, which their peer models performed in video modeling. Afterwards the subjects were expected to perform the skill when they were guided to the area where they would perform the pretend play. While the effects of least-to-most prompting and video modeling were compared, the correct and incorrect responses of the subjects were recorded and the percentage of correct response was calculated. Whether or not there was a difference between these two methods in terms of their efficiency was determined with the comparison of data concerning $(a)$ the number of sessions, $(b)$ number of trials (c) total time spent teaching and $(d)$ the number and percentage of incorrect responses until the criterion was met.

\section{General Procedure}

A pilot study was conducted with a different subject having the necessary prerequisite skills in order to predetermine the possible troubles that may arise during the procedure and how to avoid them. The pilot study was conducted by performing both teaching methods for the play skills aimed to be taught on the child to be studied. As a result of the pilot study, it was decided to carry out the research as had been planned without making any changes related to the procedure. The general procedure was composed of the probe, intervention maintenance, and generalization sessions. When the subjects gave a correct response to the skill directions presented, it was marked as "+" and when they gave an incorrect response it was marked as "-" on the data record form. The response interval was 5 seconds. The trainer organized the settings before each session and prepared the materials to be used. All sessions were recorded using a video camera. The study was conducted by the author using one-to-one teaching arrangements. In order to bring potential threats related to the internal validity of the study under control, information considering the studies on play skills which would be taught during the teaching process was presented to the subjects' families. In order to decrease the potential risk related to the teaching-order effect, the presentation of both interventions in a random order was noted.

\section{Probe Sessions}

In the study, two types of probe sessions were organized, baseline probe sessions and intermittent probe sessions.

\section{Baseline Probe Sessions}

In the study, baseline probe sessions were organized before starting each of the teaching methods and these probe sessions were maintained until three consecutive stable sets of data were gotten. The single opportunity method was used to collect data 
Table 1

Analyses of Pretend Play Skills Targeted to Be Taught

Repairing Ca

1. Puts the car in front of him or her

2. Puts the repair kit near him or her.

3. Says "oh, it is flat." showing the car's tire.

1. Places the container where pizza pieces will be put.

2. Says "let's make pizza." while looking at the container

4. Removes the flat tire from the car.

5. Puts the tire on the table.

6. Takes the pump (syringe).

7. Puts the pump head into hole in the middle of the tire. $\quad 7 . \quad$ Says "drip, drip, drip" while pretending to pour the oil.

8. Holds the pump with one hand and the piston of the pump 8. Puts the oil on the table. with the other.

9. Pushes the piston up.

9. Takes the salt (block).

10. Says "puff, puff, puff" (pretending to fill air in the tire) while 10. Pretends to pour the salt. pushing the piston up and down for at least three times.

11. Puts the pump back.

12. Says "the tire is inflated." while squeezing the tire.

13. Holds the tire.

14. Puts the tire back on the car.

15. Takes the hammer out of the repair kit.

11. Puts the salt on the table.

12. Pretends to knead the dough by opening and closing his or her fingers.

13. Says "the dough is ready" after finishing the kneading process.

14. Takes the baking tray.

16. Holds one end of the hammer toward the middle of the tire 16. Takes a pizza piece out of the container.

17. Says "knock, knock, knock," while hammering. 17 . Puts the pizza piece on the baking tray.

18. Puts the hammer back in the repair kit. 18. Takes another pizza piece out of the container.

19. Takes the screw.

20. Places the screw in the hole in the middle of the tire.

21. Says "let's screw it" while turning the screw.

22. Turns the screw at least two times.

19. Puts the other pizza piece on the baking tray

20. Opens the oven door.

21. Says "oh, the oven is hot," while looking at the oven.

23. Takes the screwdriver.

24. Places the end of screwdriver on the screw head.

25. Pretends to screw with the screwdriver.

26. Puts the screwdriver back on the repair kit.

27. Says "the repair is finished." while looking at the car.

28. Holds the car from its top.

29. Turns the car toward the garage.

30. Drives the car to the garage.

31. Parks the car in the garage.

\section{Washing Clothe}

1. Takes the clothes out of the basket.

2. Says "poof, poof," while lifting the clothes up.

3. Puts the clothes in the basket.

4. Puts the basket near the washing machine.

5. Says "let's wash the clothes."

6. Opens the washing machine door.

7. Takes the clothes out of the basket.

8. Puts the clothes inside the washing machine.

9. Closes the washing machine door.

10. Opens the detergent drawer.

11. Takes the detergent (a cylinder box).

22. Takes the container onto which pizza pieces are placed.

23. Places the baking tray in the oven.

24. Closes the oven door.

25. Pushes the oven button.

26. Waits for the oven to stop.

27. Opens the oven door when it stops.

28. Says "here it is baked," while pulling the baking tray toward them.

29. Puts the baking tray on the table.

30. Takes one piece of pizza from the tray.

31. Says "nom, nom, nom," while pretending to eat the pizza.

\section{Having Picnic}

1. Takes the picnic basket

2. Puts the picnic basket on the right seat of the car.

3. Takes the figure.

4. Puts the figure on the left seat of the car.

5 . Holds the back of the car.

6. Says "let's go," while moving the car.

7. Drives the car to the end of the road near the park.

8. Says "we're here" when reaching the end of the road.

9. Takes out the picnic basket.

10. Puts the picnic basket on the blanket.

11. Takes the figure.

12. Pretends to put the detergent into the washing machine.

13. Puts the detergent back.

14. Closes the detergent drawer.

12. Walks the figure from the car to the blanket.

13. Takes the sandwich (an eraser) from the basket

14. Says "nom nom," while putting the eraser up to the figure's mouth pretending to feed it.

15. Says "everything is okay," while looking at the washing machine. 15. Puts the sandwich on the blanket.

16. Pushes the button of washing machine.

16. Takes the fruit juice from the basket.

17. Waits for the washing machine to stop. 17 . Puts the bottle of fruit juice up to the figure's mouth pretending it is drinking.

18. Says "it is finished," after the washing machine stops.

19. Opens the washing machine door.

18. Puts the fruit juice on the blanket.

19. Takes the figure and turns its face toward the ball.

20. Takes the clothes out of the washing machine.

20. Says "it's play time," while holding the figure in his or her hand.

21. Says "it smells good," directing the cloth toward his or her nose. 21. Runs the figure towards the ball standing at the picnic area.

22. Puts the clothes in the basket.

23. Takes the basket.

22. Moves the figure toward the ball to hit it.

24. Puts the basket near the clothes line.

25. Takes the clothes out of the basket.

23. Says "I got tired," looking at the figure.

24 . Brings the figure away to the hammock.

25. Lays the figure down the hammock.

26. Says "uh, it's wet" when holding the cloth.

27. Hangs the clothes on the clothesline.

26. Says "ohhh" looking at the figure.

27. Swings the figure in the hammock. 
during the baseline probe sessions. While collecting data via single subject, the skill direction was submitted to the subject and the responses of the subject were recorded to probe for the session data collection form. The first skill step where the subject gave an incorrect response caused the assessment to end, and the other steps in the skill analysis were recorded as incorrect responses. In baseline probe sessions, correct responses were reinforced verbally and socially by using continuous reinforcement schedules. No response was accepted as an incorrect response and incorrect responses were ignored.

Baseline probe sessions were subsequently conducted. First of all, the trainer presented a special clue to draw the attention of the subject (e.g. "Do you want to play a game?"). When the subjects said they were ready for the study verbally or through a signal, the trainer reinforced them with verbal and social reinforcement (e.g. "You are great!"). Then, the skill direction was given (e.g. "play game"). The trainer waited 5 seconds for the subject to give a reaction. When the subject began to conduct the steps of the skill analysis within 5 seconds and completed at least one skill step correctly, they were reinforced (e.g. "Well done!"). When the subject gave an incorrect response he was ignored; after the first incorrect response the probe session was terminated. At the end of each session, the subject was reinforced verbally and socially for paying attention to the study and cooperating.

\section{Intermittent Probe Sessions}

Intermittent probe sessions were arranged in order to detect the performance levels of the subjects related to the pretend play taught after two intervention sessions using each teaching method. In the intermittent probe session, a trial was conducted for each of the steps in the skill analysis of pretend play with both teaching methods. In the intermittent probe sessions, the same process as stated in the baseline probe session was followed.

\section{Intervention Sessions}

Which pretend play skill would be taught for each subject during least-to-most prompting and video modeling was determined by the random assignment method. Care was taken to give at least one hour between two teaching methods and these procedures were presented in an unpredictable series. The pretend play skills that were aimed to be taught to each subject using both teaching methods are shown in Table 2. Both teaching methods were arranged in one intervention session on weekdays, and during this session, a trial for each skill step of the pretend play skills was determined. Skill steps in pretend play skills were performed by teaching all skills together. Using both teaching methods, it was continued to be taught until the subjects displayed $100 \%$ correct performance during three consecutive sessions in pretend play skills.

\begin{tabular}{lll}
\hline \multicolumn{3}{l}{ Table 2} \\
The distribution of least-to-most prompting and video \\
modeling to the subjects and pretend plays
\end{tabular}

\section{Intervention Sessions with Least to Most Prompting}

After obtaining stable data from the baseline probe, the teaching of pretend play skills using least-to-most prompting via random assignment began. In intervention sessions using least-tomost prompting, the first level was determined as independent from prompts in terms of the subjects' abilities and ease of application; gestures and verbal prompts were determined as the second level; and physical prompts and verbal prompts as the third level. The most moderate prompt was presented first to the subject, the type and intensity of the prompt being changed as needed. The transition between prompt levels occurred only when the subject gave an incorrect response for 5 seconds. Intervention sessions using least-to-most prompting were conducted subsequently. First of all, the trainer presented the subject with a special prompt, in order to draw their attention (e.g. "Do you want to play?"). When the subject expressed with a signal or verbally that he was ready for the study, the trainer gave them verbal and social reinforcement (e.g. "You are great!"). A skill direction (e.g. "play game") was then presented. The trainer waited 5 seconds for the subject to give a response. When the subject started to apply the steps of the skill analysis within 5 seconds and completed at least one skill step correctly, he was always given edible, verbal, or social reinforcement directions (e.g. "Well done!"). When the subject gave an incorrect response, gestures and verbal prompts were presented (e.g. the child was told, "take the car," while pointing at the car.). If the subject then gave a correct response, they were reinforced in the same way. If the subject gave another incorrect response, physical and verbal 
prompts were again presented (e.g. by saying "take the car," by holding their hand, guiding them to take the car.) At the end of each session, the subject was reinforced both verbally and socially for paying attention to the study and his cooperation.

\section{Intervention Sessions with Video Modeling}

In the baseline probe session, the pretend play skill assigned for video-modeling began to be taught using random assignment after getting stable data. During intervention sessions, the subject and the trainer sat side by side in front of a laptop screen. The trainer presented a prompt getting the attention of the subject in the study, and he made a statement about the study by pointing at the screen (e.g. pointing at the screen and saying "Now we are going to watch a friend playing. Do you want to watch this friend?"). When the subject expressed with a signal or verbally that he was ready for the study, he was reinforced by the trainer with verbal and social reinforcements (e.g. "Super!"). The trainer and the subject watched videos together. When the video ended, the trainer reinforced the subject verbally and socially since they had watched the video very well (e.g. "Well done! You have watched very well.") When the trainer and the subject came to the area where they would play, the trainer presented the prompt to the subject to draw their attention (e.g. "What about playing the game played by our friend?"). When the subject expressed with a signal or verbally that they were ready for the study, verbal and social reinforcements (e.g. "Well done!") were given by the trainer. Then, the trainer provided a skill direction for the subject since the skill had been performed (e.g. "play game"). When the subject completed every skill-step of the play correctly, they were continuously reinforced by the trainer with edible, verbal, and social reinforcements according to the reinforcement schedule. When the subject gave an incorrect response, it was ignored and the intervention session was finished. The subject was reinforced at the end of each session verbally and socially since they had paid attention to the study and cooperated.

\section{Maintenance and Generalization Sessions}

Maintenance sessions were arranged one, two and four weeks after the criterion was met in identified pretend play sessions. Generalization sessions were carried out with the pretest and post-test generalization probes in a different setting with different materials and different trainers after the criteria were met for the target behaviors. Pretest generalization sessions were organized after the completion of baseline probe sessions and posttest generalization sessions were organized just after the criteria were met in the play sessions. The generalization sessions, play room and acquisition materials were changed as well as the class teacher as a trainer. During the maintenance and generalization sessions, when the subject conducted all trials according to the criteria correctly, he was reinforced with verbal and social reinforcements at the end of the session. The engagement of the subject in the study was reinforced with verbal and social reinforcements by drawing his attention (e.g. "You are super!"). Except for the reinforcement directions, the same process which had been observed during the probe sessions was observed for the maintenance and generalization sessions.

\section{Reliability}

Data on dependent variable (inter-observer) and independent variable (procedural) reliability was collected in at least $30 \%$ of the sessions held during the experimental procedure. The reliability data of the study was gathered by a coder attending a doctorate program in Special Education who did not take part in the study. Dependent variable reliability data was calculated by the number of agreements divided by the number of agreements plus disagreements multiplied by 100 (Tawney \& Gast, 1984; Tekin-Iftar \& Kircaali-Iftar, 2013).

In the study, trainer behaviors observed during the probe, maintenance, and generalization sessions were as follows: (a) preparing the materials, $(b)$ drawing the attention of the subject, $(c)$ delivering skill direction, $(d)$ waiting 5 seconds for a response, (e) giving appropriate responses to the subject's responses, and $(f)$ reinforcing the attention and cooperation of the subject. Trainer behaviors observed during least-to-most prompting sessions were as follows: (a) preparing the materials, $(b)$ drawing the attention of the subject, (c) delivering skill direction, $(d)$ providing the controlling prompt correctly at increasing levels due to the response of the student, (e) giving appropriate responses to the subject's responses, and $(f)$ reinforcing the attention and cooperation of the subject. Trainer behaviors observed during video modeling sessions were as follows: (a) preparing the videos, (b) drawing the attention of the subject to watch the videos, (c) giving a response in accordance with the response of the student while watching the video, $(d)$ preparing the videos, $(e)$ drawing the attention of the subject, $(f)$ delivering skill direction, $(g)$ waiting 5 seconds for a response, $(h)$ giving appropriate responses to the 
subject's responses, and (i) reinforcing the attention and cooperation of the subject. Independent variable reliability was calculated by dividing the number of trainer behaviors observed by the number of teacher behaviors planned multiplied by 100 (Billingsley, White, \& Munson, 1980; TekinIftar \& Kircaali-Iftar, 2013). In this study, with least-to-most prompting and all experimental sessions related to video modeling, the dependent and independent reliability coefficient between the observers was calculated at $100 \%$.

\section{Social Validity}

In the study, two different social validity data sets were collected. In order to determine the convenience of the interventions presented in the teaching of pretend play skills which was the primary aim, and the importance of the findings obtained from the study from the viewpoint of the mothers, social validity data related to the opinions of the mothers was collected. Secondly, the social validity data related to the opinions of the graduate students, who were continuing their master's program of Applied Behavior Analysis in Autism in the Institute of Social Sciences of Anadolu University and had completed certain courses, were collected in order to determine the purpose of the study and the importance of the interventions used to meet this purpose as well as the findings they reached. Students who had completed the courses of "Applied Behavior Analysis Practices in Autism II" and "Applied Behavior Analysis Practices in Autism III" for their master's program and registered as graduate students were determined for the social validity study. The reason why the students were chosen according to the completion of these courses is that they had performed different interventions within the scope of the course in teaching various skills and acquired both knowledge and experience. In order to collect the social validity data, different question forms were developed for both the mothers and graduate students. In the question form developed for mothers, there were 10 questions in total, 8 multiple choice and 2 short answer questions. In the question form for the graduate students, there were 14 questions in total, 11 multiple choice and 3 short answer questions. In the multiple-choice questions on the question form, there were two answer options for the mothers, yes/no, and three answers for the graduate students, yes/no/ undecided. In the explanation section of the question forms, both mothers and graduate students were asked to mark their choice with an (X) for the multiplechoice questions, and to fill in the blanks for the short-answer questions. The trainer prepared a DVD containing videos related to the trial process for the mothers of the subjects participating in the study and an envelope containing a question form to determine their opinions related to the videos. The trainer explained the content of the videos and the question form in the envelope while giving the envelope to the mothers. Additionally, the mothers were first asked to watch the videos and fill in the question form then deliver it to the trainer. The mothers gave the question form back to the trainer after completing it.

The trainer prepared an envelope containing the question form developed to determine the opinions of the graduate students, a DVD with the videos reflecting the performance of one of the subjects during the whole trial process, and a written explanation of the research. The graduate students were asked to read the explanation first, watch the videos on the DVD second, and then fill in the question forms. Additionally, the students were asked to submit the question forms to the trainer after completing them. The data obtained from both mothers and graduate students were analyzed qualitatively.

\section{Results}

\section{Comparison of Effects: Acquisition, Maintenance and Generalization}

The data related to the effects on teaching pretend play skills aimed at Sude, Ali, and Emre for least-tomost prompting and video modeling presentation are subsequently shown in Figures 1, 2, and 3.

As it is shown in Figure 1, when the data obtained for the play skills of doing laundry and having a picnic, aimed to be taught to Sude, were analyzed, it was seen that Sude did not give any correct response during the baseline probe sessions related to the skills aimed to be taught using least-to-most prompting and video modeling presentation. Sude gave correct responses $100 \%$ of the time in the intervention sessions where both interventions were used, after eight intervention sessions in relation to the play of having a picnic using least-to-most prompting, and in relation to the play of doing laundry after 12 intervention sessions in which video modeling was presented. When the data from the maintenance phase was analyzed, it was seen that Sude demonstrated the targeted play skills with $100 \%$ accuracy after one, two, and four weeks from the finish of both interventions. In the pretest generalization session organized before teaching in terms of settings, materials, and interpersonal generalization, it was seen that Sude did not give any correct response in relation to the game skills taught with both interventions. In the 
BL

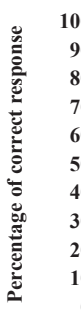

\begin{tabular}{|r|}
00 \\
90 \\
80 \\
70 \\
60 \\
50 \\
40 \\
30 \\
20 \\
10 \\
0
\end{tabular}
Intervention

$\begin{array}{llllllllllllllllllllll}1 & 2 & 3 & 4 & 5 & 6 & 7 & 8 & 9 & 10 & 11 & 12 & 13 & 14 & 15 & 16 & 17 & 18 & 19 & 20 & 21 & 22\end{array}$

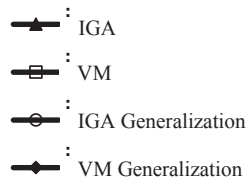

Sessions

Figure 1: Sude's percentage of correct responses related to the play skills of doing the laundry and having a picnic in baseline probe, intervention and maintenance sessions.

post-test generalization session organized after both interventions, it was seen that Sude generalized the targeted play skills at the level of $100 \%$ with regard to different settings, materials, and person.

As presented in Figure 2, when the data obtained for the play skills of repairing a car and making a pizza, aimed to be taught to Ali, were analyzed, it was seen that Ali gave correct responses at the level of 3.2\% for each baseline probe session related to the play of repairing a car taught using presenting least-to-most prompting. For the play of making a pizza taught using video modeling, it was seen that Ali gave a correct response at the level of approximately $2.1 \%$ (range $=0 \%-3.2 \%$ ) during the baseline probe sessions. In the intervention phase in which both interventions were presented, Ali gave a correct response 100\% of the time in relation to the play of repairing a car after 14 intervention sessions in which teaching was presented using least-to-most prompting; and after 18 intervention sessions in relation to the play of making a pizza using video modeling. When the data of the maintenance phase was analyzed, it was seen that Ali demonstrated the targeted play skills at
$100 \%$ accuracy after one, two, and four weeks from the finish of both interventions. It was seen that Ali gave a correct response at the level of $3.2 \%$ for teaching using least-to-most prompting in relation to the play skills taught in the pretest generalization session organized before teaching in terms of settings, materials, and interpersonal generalization. He did not give any correct response for the teaching with video modeling. In the post-test generalization session organized after both interventions. İt was seen that Ali generalized the targeted play skills at the level of $100 \%$ with regard to different settings, materials, and person.

As is shown in Figure 3, when the data obtained for the play skills of repairing a car and making a pizza, aimed to be taught to Emre, were analyzed, it was seen that Emre gave a correct response at the level of 3.2\% for each baseline probe session related to the play of making a pizza taught by presenting least-to-most prompting. For the play of repairing a car taught with video modeling, it was seen that Emre did not give any correct response in the baseline probe session. In the intervention phase in which both teaching methods

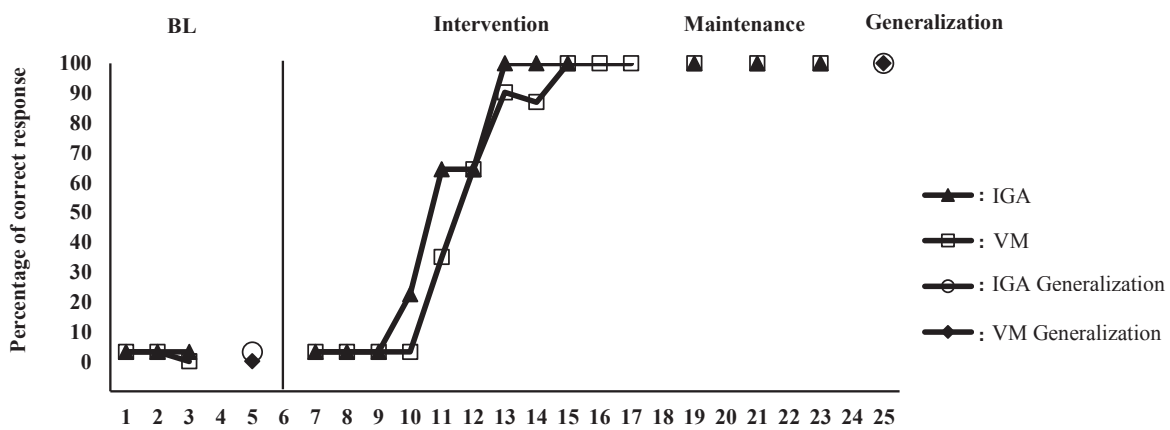

Figure 2: Ali's percentage of correct responses related to the play skills of repairing a car and making a pizza in baseline probe, intervention and maintenance sessions. 
BL

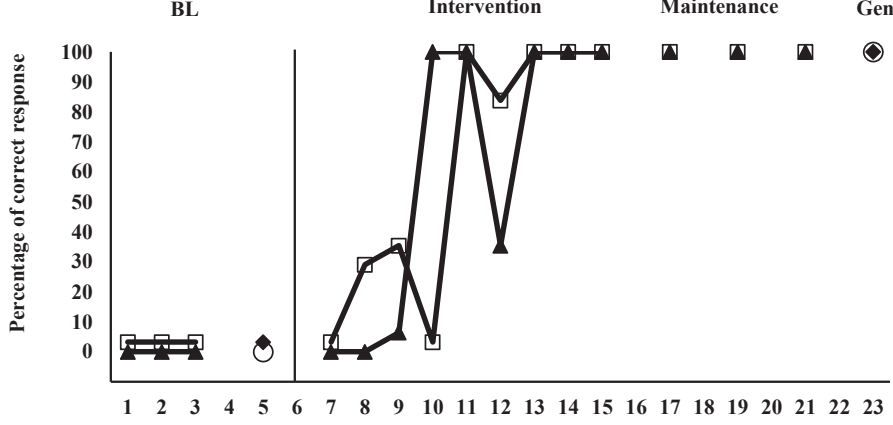

Generalization

\section{Sessions}

Figure 3: Emre's percentage of correct responses related to the play skills of repairing a car and making a pizza in baseline probe, intervention and maintenance sessions.

were presented, Emre gave a correct response 100\% of the time after eight intervention sessions in relation to the play of making a pizza using least-tomost prompting; and after ten intervention sessions in relation to the play of repairing a car using video modeling. Emre's performance decreased to $35.4 \%$ after the tenth intervention session in which teaching was presented with least-to-most prompting, and to the level of $83.8 \%$ after the tenth intervention session in which video modeling was presented. However, after 14 intervention sessions in which both interventions were presented, Emre's performance reached a $100 \%$ degree of accuracy. When data from the maintenance phase was analyzed, it was seen that Emre demonstrated the targeted play skills with 100\% degree of accuracy after one, two, and four weeks from the finish of both interventions. It was seen that Emre did not give any correct response for the teaching with least-to-most prompting in relation to the play skills taught in the pretest generalization session organized before teaching in terms of settings, materials, and interpersonal generalization. He gave a correct response at the level of $3.2 \%$ with video modeling. In the post-test generalization session organized after both interventions, it was seen that Emre generalized the targeted play skills at the level of $100 \%$ with regard to different settings, materials, and person.

\section{Comparison of Efficiency}

Data was collected related to $(a)$ number of sessions, (b) trial number, $(c)$ total teaching time, and $(d)$ number and percentage of incorrect responses occurring until the criteria were met in order to detect whether or not there was a difference in terms of the efficiency of least-to-most prompting and video modeling. The data obtained in relation to efficiency are presented in Table 3.
According to the efficiency data presented in Table 3 , Sude gave a correct response at the level of $100 \%$ for the doing laundry play skill after 12 intervention sessions using least-to-most prompting, and after 16 intervention sessions for the having a picnic play skill using video modeling. 12 trials were made for teaching the doing laundry play skill and 16 trials were made for teaching the play skill of having a picnic until Sude gave a response at the criteria level. Sude gave 69 incorrect responses (42.5\%) in the intermittent probe sessions until meeting the criteria for the play skill of doing laundry, and $90(41.6 \%)$ incorrect responses in total during the intermittent probe sessions until meeting the criteria for the play skill of having a picnic. When the total time of the intervention sessions performed during both interventions was examined, it was seen that the intervention sessions with least-to-most prompting lasted a total of 23 minutes 15 seconds until meeting the criteria, and the intervention sessions with video modeling lasted for 42 minutes 31 seconds total.

Ali gave a response with $100 \%$ accuracy in relation to the play of repairing a car after 18 intervention sessions using least-to-most prompting, and after 22 intervention sessions in relation to the play of making a pizza using video modeling. 18 trials were made for teaching the play skill of repairing a car, and 22 trials were made for teaching the play of making pizza until Ali gave a response at the criteria level. Ali gave 136 incorrect responses $(48.7 \%)$ in total during the intermittent probe sessions until meeting the criteria for the play skill of repairing a car, and he gave 162 (47.5\%) incorrect responses in total during the intermittent probe sessions until meeting the criteria for the play skill making a pizza. When the total time for the intervention sessions performed during both interventions was 


\begin{tabular}{|c|c|c|c|c|c|}
\hline Participants & Intervention-Play & Session number & Trial number & $\begin{array}{l}\text { Incorrect response number/ } \\
\text { Percentage }\end{array}$ & $\begin{array}{l}\text { Teaching time } \\
\text { (h:min:s) }\end{array}$ \\
\hline \multirow{2}{*}{ Sude } & VM - Having a picnic & 16 & 16 & $90 / 41.6 \%$ & $00: 42: 31$ \\
\hline & LMP - Doing laundry & 12 & 12 & $69 / 42.5 \%$ & $00: 23: 15$ \\
\hline \multirow{2}{*}{ Ali } & VM - Making pizza & 22 & 22 & $162 / 47.5 \%$ & 01:01:01 \\
\hline & LMP - Repairing a car & 18 & 18 & $136 / 48.7 \%$ & $00: 51: 46$ \\
\hline \multirow{2}{*}{ Emre } & VM - Repairing a car & 18 & 18 & $107 / 38.3 \%$ & 01:02:11 \\
\hline & LMP - Making pizza & 18 & 18 & $111 / 39.7 \%$ & $00: 45: 15$ \\
\hline
\end{tabular}

examined, it was seen that the intervention sessions using least-to-most prompting lasted for 51 minutes 46 seconds in total, and the intervention sessions with video modeling lasted for 1 hour 1 minute and 1 second until the criteria was met.

Emre gave a response with $100 \%$ accuracy in relation to the play skills of making a pizza and repairing a car after 18 intervention sessions using the teaching application of least-to-most prompting for making a pizza, and video modeling for repairing a car. 18 trials were made for teaching the play of making a pizza, as well as the play of repairing a car until Emre gave a response at the criteria level. Emre gave 111 incorrect responses $(39.7 \%)$ in total during the intermittent probe sessions until he met the criteria for the play of making a pizza, and he gave 107 (38.3\%) incorrect responses in total during the intermittent probe sessions until he met the criteria for the play of repairing a car. When the total time of the intervention sessions performed for both interventions was examined, it was seen that the intervention sessions using least-to-most prompting lasted for 45 minutes 15 seconds in total, and the intervention sessions with video modeling lasted for 1 hour 2 minutes and 11 seconds until the criteria was met.

\section{Social Validity}

In order to detect the importance of the goals of this research, the interventions used to meet these goals, and the findings obtained, social validity data was collected in relation to the viewpoints of the subjects' mothers and the graduate students. These graduate students were studying for their master's of Applied Behavior Analysis in Autism in the Institute of Social Sciences at Anadolu University and had completed specific courses. According to the social validity data collected from the mothers of the subjects participating in the research, the mothers stated that teaching pretend play skills to their children is important and this teaching will contribute to their child's social development, especially their interaction with their peers. The mothers also stated that they were pleased with showing video images to their children while teaching pretend play skills and that their children learned pretend play skills thanks to both teaching techniques. In addition, the mothers stated that aside from the play skills taught in this study, their children were in need of being taught other play skills. The mothers also stated that their children could use these pretend play skills at home and in the institution they are attending (e.g. kindergarten, etc.), and these skills reflect positively on game play in different settings such as home, school, and so forth. Additionally, the mothers stated that they were satisfied with the participation in this study. When the mothers were asked which aspects of the study they were satisfied with, the mothers of all subjects stated that they were pleased with the fact that their children could play games and speak while playing games, and they could carry out the applications which drew their attention, were liked by them, and were useful. One of the mothers expressed her satisfaction by saying, "Countless thanks for your training. You have turned a sapling into a tree." When the mothers were asked which aspects of the study they were dissatisfied with, all of them stated that there was no aspect that they were dissatisfied with.

Social validity data was collected from all 15 graduate students, providing features defined for the social validity study. According to the social validity data of the study, all graduate students stated that it was important and necessary to teach pretend play skills to children with ASD. Also, all graduate students stated that teaching with both video modeling and leastto-most prompting was effective in teaching various skills to children with ASD. Although one of them was indecisive, 14 graduate students expressed their thoughts that teaching with both video modeling and least-to-most prompting could be easily used in oneto-one training performed with children having ASD. All graduate students stated that teaching pretend play skills will contribute to the social development of the students and especially to their interaction with their 
peers. Nine of the 15 graduate students expressed the viewpoint that the preparations made for the process of video modeling were not troublesome or costly, three of them stated that they were troublesome and costly, and three of them stated that they were indecisive about this matter. All graduate students stated that the preparations made for teaching with least-to-most prompting were not troublesome or costly. While 11 of the 14 graduate students stated that the process of video modeling could be easily used in group training conducted on children with ASD, three of them stated that they were indecisive regarding this matter, and one stated that it was negative. While nine graduate students stated that teaching with least-to-most prompting could be easily used in group training conducted with children having ASD, four graduate students stated that they were indecisive regarding this matter, and two of them stated that it was not easy. All graduate students stated that doing research regarding teaching pretend play skills to the children with ASD was necessary. Seven of the graduate students stated that they preferred to use video modeling while teaching skills aside from play skills to children with ASD. Three of them stated that they preferred to use teaching using least-tomost prompting. Five of them preferred to use both interventions. The ones who preferred only video modeling said it was because it could be applied easily, from their studies they found it was effective, individuals with ASD responded more easily to visual stimuli, it could be used for other children more than once after it was prepared, and it was cost-effective. The ones who preferred only least-to-most prompting stated that they preferred it because in multiple-step skills teaching, while watching the models a child may miss some of the steps due to loss of attention, video modeling requires preliminary preparation compared to teaching with least-to-most prompting, it was not always possible to find a suitable model, behavior or environment, and it was more effective. One of those who preferred both teaching methods stated that he would use the intervention which was most suitable for the skill. Another one stated that he preferred to use both interventions together with the thought that video modeling would provide an advantage to children with ASD in terms of strengthening their visual memories while on the other hand, prompts would motivate children due to their necessity. Three graduate students stated that they preferred to use video modeling for social interaction, communication and daily life skills, and least-to-most prompting is useful for teaching safety or academic skills. When the graduate students were asked which aspects of this study they liked the most, all of them stated that they liked the convenience of the play materials used, the use of evidence based practices, the play skills were enjoyable for the children, teaching pretend play skills is an important competency individuals with ASD lack, giving space to verbal expression for these skills, providing generalization and convenience of the games chosen, and being pleased with their content. On the other hand, when the graduate students were asked what aspects of this study they did not like, nine graduate students stated that there was no aspect of the study they did not like. Six graduate students stated their opinions as recommending further researches related to using play dough during the games, choosing play skills better suited for daily life like baking bread, diversification of reinforcements, teaching in inclusive settings, and producing play skills on their own.

\section{Discussion}

In this research, the comparison of the effects and efficiency of least-to-most prompting and video modeling in teaching pretend play skills to children with autism spectrum disorder was aimed. Furthermore, in order to determine the social validity of the study, the opinions of the families of the children participating in the research and the graduate students studying for their master's of Applied Behavior Analysis in Autism in the Institute of Social Sciences at Anadolu University were examined. In the following section, the research is discussed from different points based on the research findings and recommendations are made for further research.

The findings of the research demonstrated that there was no difference in terms of effectiveness between teaching with least-to-most prompting and video modeling for teaching chain pretend-play skills to children with ASD. In literature, no research comparing the effect and efficiency of teaching using least-to-most prompting and video modeling was encountered in regard to teaching chain skills to individuals with ASD. However, in only one research performed regarding this subject up until now, it was seen that the presentation of teaching using least-to-most prompting together with video modeling for teaching chain skills to children with ASD was compared in terms of effect only with the presentation (Murzynski \& Bourret, 2007). The effect findings obtained from this study show consistency with the findings of the comparison study conducted by Murzynski and Bourret (2007). Additionally, the findings of this research show similarity with the findings of studies previously conducted which 
compared using video modeling with other methods for teaching pretend play skills, including role play skills, to individuals with ASD (Akmanoglu et al., 2014; Lydon et al., 2011). Unlike this study, however, in the study of Akmanoglu et al. (2014), it was concluded that presenting video modeling with graduated guidance for only one subject was more effective than presenting it alone. In addition to this, the study of Lydon et al. (2011) report that they were able to reach their criteria at the level of $90 \%$ correct for two out of five children with pivotal response training using the presentation of video modeling. Therefore, this research can be thought to both support and expand the findings of previous research conducted in relation to this subject.

When the findings on the effects of the research were examined independently in terms of teaching using least-to-most prompt and video modeling, it was seen that both teaching methods are effective in teaching pretend play skills. From this aspect, the research shows similarity with the findings of other studies questioning the effects of teaching using least-to-most prompting in teaching pretend play skills (Barton \& Wolery, 2010; Kasari et al., 2006) as well as the use of video modeling (Boudreau \& D'Entremont, 2010; MacDonald et al., 2009; Scheflen et al., 2012). When the findings obtained from this research are examined regarding the teaching of pretend play skills from a different viewpoint, it is seen that pretend play skills are designed without considering the types and features of pretend play in previous studies (Hobson et al., 2009; Kasari et al., 2006; Lydon et al., 2011). However, in only one of these conducted researches, it was seen that pretend play in which all types and features are taken into consideration without a certain topic of play by presenting teaching using least-to-most prompting was taught (Barton \& Wolery, 2010). In this research, different from previous studies on this subject, teaching pretend play skills including all types and features of pretend play was conducted within a definite play topic. The findings of this research show similarity with the findings of the studies conducted by other researchers in relation to this subject. Therefore, it can be suggested that this research supports the mentioned research findings and contributes to the literature.

The findings of the research related to the effect of both teaching methods for protecting the maintenance of pretend plays indicate that pretend play skills taught with these teaching methods are kept at the correctness level of $100 \%$ one, two, and four weeks after being taught. In the study of Murzynski and Bourret (2007) in which video modeling was presented together with least-to-most prompting and alone, it was seen that systematic maintenance data related to keeping a certain level of correctness after teaching chain skills was not collected. Therefore, independent variables were not compared in terms of maintenance. In addition to this, in the literature, it is noteworthy that independent variables in some comparison studies with different teaching methods using leastto-most prompting and video modeling as different independent variables were not evaluated in terms of providing the maintenance of targeted skills (Charlop-Christy et al., 2000; Libby et al., 2008). On the other hand, when comparison studies in which maintenance data related to the subject are examined, it is seen that the maintenance findings obtained from this research show consistency with the findings of previous research (Akmanoglu et al., 2014; Lydon et al., 2011; Sancho et al., 2010). In the light of all these researches, it can be thought that the maintenance findings of this research support and expand the results in literature.

When the effects of presenting teaching using least-to-most prompting and video modeling on generalization are examined, it is seen that there is no difference between the two methods in terms of generalization; and the generalization among settings, materials and people was performed $100 \%$ correct by all subjects. In the study conducted by Murzynski and Bourret (2007), it is worth noting that the applications compared were not examined in terms of generalization. On the other hand, when the researches in which both independent variables are compared by using different teaching methods are examined, it is seen that the generalization findings of this research show similarity with the findings of the previous researches (Akmanoglu et al., 2014; Charlop-Christy et al., 2000; Libby et al., 2008; Lydon et al., 2011; Sancho et al., 2010). Since any study comparing both independent variables in the research in terms of generalization was not encountered in literature, it can be suggested that the findings in this study expand the findings in literature and support the existing findings.

When the parameters of efficiency of the two independent variables in the research are compared, some differences are seen. When the efficiency results are examined in terms of intervention session, number of trials, and number/percentage of incorrect responses, for both subjects, Sude and Ali, teaching with least-to-most prompting was seen to be more efficient in comparison to video modeling. For the 
other subject (Emre), no difference was seen between the efficiency findings related to both methods in terms of intervention sessions and trial numbers. However, the number and percentage of incorrect responses was a little higher in teaching using leastto-most prompting. Additionally, when the efficiency results are examined in terms of the total time passed until the criteria was met during the intervention sessions where both teaching methods are presented, it was seen that teaching using least-to-most prompting is more efficient in all subjects compared to teaching with video modeling. When the efficiency results obtained from the research are discussed from all aspects, it is noteworthy that teaching using least-to-most prompting is more efficient for Sude and Ali. In the study conducted by Murzynski and Bourret (2007), it was seen that the methods using least-to-most prompting with video modeling is more efficient compared to being presentation alone in terms of the number of trials conducted until criteria is met and the number of steps in which the prompt is presented. In another study, it is seen that the presentation of video modeling together with teaching through graduated guidance is more efficient compared to being used alone (Akmanoglu et al., 2014). In addition, some studies in which other interventions such as pivotal response training using the presentation of video modeling on its own, being a true model, and so forth are compared, it is reported that the teaching time is shorter for video modeling. In other words, it is stated that learning occurs more rapidly when teaching with video modeling is presented (Charlop-Christy et al., 2000; Lydon et al., 2011). However, in the study in which the teaching methods using most-to-least prompting and leastto-most prompting are compared, it reached the result that teaching is performed more rapidly using least-to-most prompting but with a higher number of errors (Libby et al., 2008). According to the findings of the previous research, it was seen that teaching using video modeling increases efficiency when presented with different prompting procedures. However, the findings of Libby et al. (2008) leave the question of which method is more efficient when presented alone. Therefore, this research is thought to expand the literature since least-to-most prompting was compared to video modeling for teaching pretend play skills in terms of efficiency parameters.

The social validity findings of the research indicate that the mothers of the subjects and the graduate students expressed positive opinions about the study. In the researches comparing teaching using leastto-most prompting with video modeling and other methods encountered in the literature, it is worth noting that the dimension of social validity was not examined, (Libby et al., 2008; Murzynski \& Bourret, 2007); or it was examined in a limited number of studies that compared teaching using video modeling with other methods (Akmanoglu et al., 2014; Sancho et al., 2010). The findings obtained from the researches comparing teaching using video modeling and other methods show consistency with the social validity findings of this research. In the previous researches, since social validity studies were never mentioned or were mentioned in a limited way, this research can be thought to both support the literature and contribute to it. In addition to the social validity findings obtained from this research, in the period when all processes of the research were completed, parent interviews continued, and it was seen that sharing the opinions of the mothers during these interviews was remarkable. One of the mothers stated that her child produced pretend plays with the objects found in their free time, and they played these games with their peers. Another one stated that her child played with the toys at home more imaginatively and started using verbal expressions while playing with them. Another mother stated that her child played games more interactively with peers than before.

The findings obtained from the research show that both interventions are effective. However, there are some limitations of the research. First of all, the research is limited by having only three subjects with ASD and teaching only pretend play skills targeted for each subject. Secondly, the performance of the subjects was evaluated by using the single opportunity method. Therefore, which teaching application caused which type of incorrect response the most in teaching pretend plays as chain skills cannot be defined. Thirdly, although the generalization sessions of the research were performed in the play room of the institution where the subjects were continuing with different play tools and different individuals, the fact that these generalization sessions were performed only in this institution can be thought of as a limitation.

In the light of the limitations of the research and the findings obtained, the following recommendations for further researches can be made: (a) Similar studies can be performed with the subjects having different features (e.g. with the individuals having different types and levels of incompetency), with different trainers (e.g. with parents and teachers), in different environments (e.g. in inclusive settings, at home) and in teaching different skills (e.g. different discrete or chain skills); (b) Be different from this study by organizing one-to-one training, 
the effects and efficiency of teaching using least-tomost prompting and video modeling during group training can be compared. (c) Both least-to-most prompting and video modeling can be compared with other response prompting procedures or evidence based practices (e.g. pivotal response training, etc.) in terms of efficiency and effectiveness.

As a result, in the research no difference was found between teaching with least-to-most prompting and video modeling in terms of their effectiveness. For this reason, the trainers working in a private teaching field can be recommended to prefer teaching with least-to-most prompting or video modeling depending on which one is suitable according to the skills aimed at being taught and the features of the individuals. The efficiency finding of the research showed that teaching using least-tomost prompting was more effective than teaching with video modeling. However, neither of these two teaching processes is seen as sufficient enough to be recommended more, and it is thought that more research must be done considering this matter.

Author's note: I extend my endless thanks to the children and their families who participated in the research process, to Research Assistant Ozlem Dalgin-Eyiip who collected the reliability data and to Prof. Dr. Gonul Kircaali-Iftar who shared her esteemed opinions about the study.

\section{References}

Akmanoglu, N., Yanardag, M., \& Batu, E. S. (2014). Comparing video modeling and graduated guidance together and video modeling alone for teaching role playing skills to children with autism. Education and Training in Autism and Developmental Disabilities, 49, 17-31.

Allen, K. D., Wallace, D. P., Renes, D., Bowen, S. L., \& Burke, R. V. (2010). Use of video modeling to teach vocational skills to adolescents and young adults with autism spectrum disorders. Education and Treatment of Children, 33, 339-349.

American Psychiatric Association. (2013). Diagnostic and Statistical Manual of Mental Disorders (DSM-5) (5th ed.).

Washington, DC: Author.

Amerikan Psikiyatri Birliği (American Psychiatric Association). (2001). Psikiyatride hastalikların tanımlanmast ve sinıflandirılması el kitabi, Yeniden Gözden Geçirilmiş Dördüncü Baskı (Handbook for Identified and Classified of Diseases in Psychiatry, Revised Fourth Edition)(DSM-IV-TR) (trans. E. Koroglu). Ankara: Hekimler Yayın Birliği.

Ault, M. J., \& Griffen, A. K. (2013). Teaching with the system of least prompts: An easy method for monitoring progress. Teaching Exceptional Children, 45, 46-53.

Barton, E. E. (2010). Development of a taxonomy of pretend play for children with disabilities. Infants and Young Children, 23, 247-261.
Barton, E. E., \& Pavilianis, R. (2012). Teaching pretend play to young children with autism. Young Exceptional Children, 15, 5-17.

Barton, E. E., \& Wolery, M. (2008). Teaching pretend play to children with disabilities: A review of the literature. Topics in Early Childhood Special Education, 28, 109-125.

Barton, E. E., \& Wolery, M. (2010). Training teachers to promote pretend play in young children with disabilities. Exceptional Children, 77, 85-106.

Billingsley, F., White, O. R., \& Munson, R. (1980). Procedural reliability: A rationale and an example. Behavioral Assessment, 2, 229-241.

Boudreau, E., \& D'Entremont, B. (2010). Improving pretend play skills of preschoolers with autism spectrum disorders: The effects of video modeling. Journal of Developmental and Physical Disabilities, 22, 415-431.

Charlop, M. H., Dennis, B., Carpenter, M. H., \& Greenberg, A. L. (2010). Teaching socially expressive behaviors to children with autism through video modeling. Education \& Treatment of Children, 33, 371-393.

Charlop-Christy, M. H., Le, L., \& Freeman, K. A. (2000). A comparison of video modeling with in vivo modeling for teaching children with autism. Journal of Autism and Developmental Disorders, 30, 537-552. 
Cihak, D., Fahrenkrog, C., Ayres, K. M., \& Smith, C. (2010). The use of video modeling via a video IPod and a system of least prompts to improve transitional behaviors for students with autism spectrum disorders in the general education classroom. Journal of Positive Behavior Interventions, 12, 103-115.

Hobson, J. A., Hobson, R. P., Malik, S., Bargiota, K., \& Calo, S. (2013). The relation between social engagement and pretend play in autism. British Journal of Developmental Psychology, 31, 114-127.

Hobson, R. P., Lee, A., \& Hobson, J. A. (2009). Qualities of symbolic play among children with autism a socialdevelopmental perspective. Journal of Autism and Developmental Disorders, 39, 12-22.

Kasari, C., Freeman, S., \& Paparella, T. (2006). Joint attention and symbolic play in young children with autism: a randomized controlled intervention study. Journal of Child Psychology and Psychiatry, 47, 611-620.

Kircaali-Iftar, G. (2012). Otizm spektrum bozukluğuna genel bakıs (An overview to autism spectrum disorders). In E. Tekin-Iftar (Ed.), Otizm spektrum bozukluğu olan çocuklar ve eğitimleri (Children with autism spectrum disorders and their education) (pp. 17-46). Ankara: Vize Yayınları.

Kurt, O. (2012). Uyarlamalı dönüşümlü uygulamalar modeli (An adapted alternating treatment model). In E. Tekin-Iftar (Ed.), Eğitim ve davranıs bilimlerinde tek denekli araștırmalar (Single Subject Research in Educational and Behavioral Sciences) (pp. 329-349). Ankara: Türk Psikologlar Derneği Yayınları.

Lam, Y. G., \& Yeung, S. S. (2012). Cognitive deficits and symbolic play in preschoolers with autism. Research in Autism Spectrum Disorders, 6, 560-564.

Libby, M. E., Weiss, J. S., Bancroft, S., \& Ahearn, W. H. (2008). A comparison of most-to-least and least-tomost prompting on the acquisition of solitary play skills. Behavior Analysis in Practice, 1, 37-43.

Lifter, K., Ellis, J., Cannon, B., \& Anderson, S. R. (2005). Developmental specificity in targeting and teaching play activities to children with pervasive developmental disorders. Journal of Early Intervention, 27, 247-267.

Lifter, K., Foster-Sanda, S., Arzamarski, C., Briesch, J., \& McClure, E. (2011). Overview of play: Its uses and importance in early intervention/early childhood special education. Infants and Young Children, 24, 225-245.

Lifter, K., Sulzer-Azaroff, B., Anderson, S., \& Cowdery, G. (1993). Teaching play activities to preschool with disabilities: The importance of developmental considerations. Journal of Early Intervention, 17, 139-159.

Lovaas O. I. (2003). Teaching individuals with developmental delays: Basic intervention techniques. Austin, TX: Pro-Ed.

Lydon, H., Healy, O., \& Leader, G. (2011). A comparison of video modeling and pivotal response training to teach pretend play skills to children with autism spectrum disorder. Research in Autism Spectrum Disorders, 5, 872-884.

MacDonald, R., Sacromone, S., Mansfield, R., Wiltz, K., \& Ahearn, W. (2009). Using video modeling to teach reciprocal pretend play to children with autism. Journal of Applied Behavior Analysis, 42, 43-55.

Mason, R. A., Ganz, J. B., Parker, R. I., Boles, M. B., Davis, H. S., \& Rispoli, M. J. (2013). Video-based modeling: differential effects due to treatment protocol. Research in Autism Spectrum Disorders, 7, 120-131.
Mason, R. A., Ganz, J. B., Parker, R. I., Burke, M. D., \& Camargo, S. P. (2012). Moderating factors of video modeling with other as model: A meta-analysis of singlecase studies. Research in Developmental Disabilities, 33, 1076-1086.

Murzynski, N. T., \& Bourret, J. C. (2007). Combining video modeling and least-to-most prompting for establishing response chains. Behavioral Interventions, 22, 147-152.

Palechka, G., \& MacDonald, R. (2010). A comparison of the acquisition of play skills using instructor-created video models and commercially available videos. Education and Treatment of Children, 33, 457-474

Phillips, N., \& Beavan, L. (2012). Teaching play to children with autism (2nd ed.). Los Angeles, CA: Sage.

Rosenberg, N., E., Schwartz, I. S., \& Davis, C. A. (2010). Evaluating the Utility of Commercial Videotapes for Teaching Hand Washing to Children with Autism, Education and Treatment of Children, 33, 443-455.

Rutherford, M. D., Young, G. S., Hepburn, S., \& Rogers, S. J. (2007). A longitudinal study of pretend play in autism. Journal of Autism and Developmental Disorders, 37, 10241039.

Sancho, K., Sidener, T. M., Reeve, S., \& Sidener, D. W. (2010). Two variations of video modeling interventions for teaching play skills to children with autism. Education and Treatment of Children, 33, 421-442.

Scheflen, S. C., Freeman, S. F. N., \& Paparella, T. (2012). Using video modeling to teach young children with autism developmentally appropriate play and connected speech. Education and Training in Autism and Developmental Disabilities, 47, 302-318.

Shukla-Mehta, S., Miller, T., \& Callahan, K. J. (2010). Evaluating the effectiveness of video instruction on social and communication skills training for children with autism spectrum disorders: A review of the literature. Focus on Autism and Other Developmental Disabilities, 25, 23-36.

Tawney, J. W., \& Gast, D. L. (1984). Single subject research in special education. Columbus, $\mathrm{OH}$ : Merrill.

Tekin-Iftar, E., \& Kircaali-Iftar, G. (2013). Özel eğitimde yanlışsiz ögrretim yöntemleri (Errorless teaching methods in special education) (3th ed.). Ankara: Nobel Yayıncllik.

Ulke-Kurkcuoglu, B. (2012). Otizm spektrum bozukluğu olan çocuklara oyun becerilerinin öğretimi (Teaching play skills to children with autism spectrum disorders). In E. Tekin-Iftar (Ed.), Otizm spektrum bozukluğu olan çocuklar ve eğitimleri (Children with autism spectrum disorders and their education) (pp. 423-471). Ankara: Vize Yayınları.

Wolfberg, P. J. (1999). Play and imagination in children with autism. New York, NY: Teachers College Press.

Wong, C., Odom, S. L., Hume, K., Cox, A. W., Fettig, A., Kucharczyk, S. ... Schultz, T. R. (2014). Evidence-based practices for children, youth and young adults with autism spectrum disorders. Chapel Hill, NC: University of North Carolina, Frank Porter Graham Child Development Institute, Autism Evidence-Based Practice Review Group.

Yanardag, M., Birkan, B., Yllmaz, I., Konukman, F., Agbuga, B., \& Lieberman, L. (2011). The effects of least-tomost prompting procedure in teaching basic tennis skills to children with autism. Kinesiology, 43, 44-55. 